\title{
Dactyloctenium aegyptium (L.) Willd. (Poaceae), novedad para Andalucía (España)
}

\author{
Adolfo F. Muñoz Rodríguez ${ }^{1}$, Enrique Sánchez Gullón² \& Juan Antonio Devesa Alcaraz ${ }^{3}$ \\ 1Dpto. Ciencias Integradas. Universidad de Huelva, Huelva 21071, España. \\ ${ }^{2}$ Paraje Natural Marismas del Odiel (Huelva), Ctra. del Dique Juan Carlos I Km 3, Apdo., 720, E-21071 Huelva, España. \\ ${ }^{3}$ Dpto. de Botánica, Ecología y Fisiología Vegetal, Facultad de Ciencias, Universidad de Córdoba. Edificio José Celestino \\ Mutis, Campus de Rabanales, Universidad de Córdoba, Córdoba 14071, España.
}

\section{Correspondencia}

E. Sánchez Gullón

e-mail: enrique.sanchez.gullon@juntadeandalucia.es

Recibido: 7 noviembre 2018

Aceptado: 24 julio 2019

Publicado on-line: 26 septiembre 2019

Editado por: B. Cabezudo
Dactyloctenium aegyptium (L.) Willd. (Poaceae), new for Andalusia (Spain)

palabras clave: Dactyloctenium aegyptium, Poaceae, novedad para Andalucia (España)

key words: Dactyloctenium aegyptium, Poaceae, novelty for Andalusia (Spain)
Dactyloctenium aegyptium (L.) Willd., Enum. PI.: 1029 (1809)

Cynosurus aegyptius L., Sp. PI.: 72 (1753)

ESPAÑA, Almería: Almería capital, 15/09/1995, Leg: E. Dana (HUAL14169 y HUAL14171).

Dactyloctenium aegyptium es una especie nativa de las zonas tropicales y subtropicales de África y Asia (Stone, 1970), y como tal se indica también para la mayoría de los países africanos y asiáticos de la Cuenca Mediterránea (Valdés \& Scholz, 2009), si bien se considera introducida en Marruecos (Tanji \& Taleb, 1997). Se trata de un xenófito efemerófito, en expansión sobe todo en medios urbanos alterados y en suelos arenosos costeros, que se ha introducido en el norte, centro y sur de América, en diversos países asiáticos y europeos, y en Oceanía. En Europa se conoce naturalizada de Italia (Arcangeli, 1894), y de Bélgica, Chipre, República Checa, Grecia y Eslovaquia (Meikle, 1985; CABI, 2018; DAISIE, 2018).

Su presencia en la Península Ibérica fue dada a conocer por Verloove \& Sánchez (2008) en las zonas costeras de Barcelona y, más recientemente, de nuevo en Barcelona (Pyke, 2013), y también en las provincias de Alicante y Valencia (Aragoneses \& al., 2011; Laguna \& al., 2009). La población detectada en el casco de la ciudad de Almería, amplía el área conocida de la especie en la Península lbérica y constituye una novedad para la flora de Andalucía. La cita es interesante además por estar basada en el material que tal vez sea más antiguo conocido de este taxón para el territorio, pues fue recolectado en 1995, aunque erróneamente identificado como Eleusine tristachya (Lam.) Lam. Esta última especie es, ciertamente, muy parecida, pero sus especímenes presentan los lemas múticos, y no aristados como es característico en Dactyloctenium aegyptium.

\section{Agradecimientos}

Este trabajo se ha efectuado en el marco de los Proyectos CGL2014-52787-C3-3-P y CGL2017-85204C3-3-P, financiados por el Ministerio de Economía y Competitividad, y cofinanciados con fondos FEDER.

\section{Bibliografía}

Aragoneses, I., Martínez Flores, F., Alonso, M.A., Martínez Azorín, M., Camuñas, E., Souba, G.J. \& Crespo, M.B. (2011). Notas y comentarios a la flora iberolevantina. Flora Montiberica, 47, 57-70.

Arcangeli, G. (1894). Compendio della flora italiana. Ermanno Loescher. Torino.

CABI (2018). Dactyloctenium aegyptium by RojasSandoval, J. En: Invasive Species Compendium. Wallingford, UK: CAB International. https://www.cabi. org/ISC/datasheet/19321 [consultado 25 octubre 2018].

DAISIE (2018). European Invasive Alien Species Gateway. http://www.europe-aliens.org/speciesFact sheet.do?speciesld=3425\# [consultado 25 octubre 2018].

Laguna, E, Pablo Ferrer, P., Collado-Rosique, F. \& 
Vizcaino-Matarredona, A. (2009). Primera cita de Dactyloctenium aegyptium (L.) Willd. (Poaceae) en la Comunitat Valenciana. Studia Botanica, 28, 175-178. Meikle, R.D. (1985). Flora of Cyprus, vol. II. BenthamMoxon Trust. Kew.

Pyke, S. (2013). Notes on xenophytes detected in Catalonia, Spain. Collectanea Botanica, 32, 83-86.

Stone, B. (1970). The flora of Guam. Micronesica, 6, $1-659$.

Tanji, A. \& Taleb, A. (1997). New weed species recently introduced into Morocco. Weed Research, 37(1), 2731.

Valdés. B. \& Scholz, H (2009). Poaceae (pro parte majore). Euro+Med PlantBase - the information resource for Euro-Mediterranean plant diversity. http:// ww2.bgbm.org/EuroPlusMed/ [consultado 25 octubre 2018].

Verloove, F. \& Sánchez Gullón, E. (2008). New records of interesting xenophytes in the Iberian Peninsula. Acta Bot. Malacitana, 33, 147-167. 